\title{
Effect of High Intensity Interval Training with Changes in Inclination to Irisin of Men with Overweight and Obesity
}

\author{
Natanael Sinulingga ${ }^{a}$, Sri Mardjiati Mei Wulan ${ }^{\mathrm{a}, \mathrm{b}}$, Indrayuni Lukitra Wardani ${ }^{\mathrm{a}}$, \\ Meisy Andriana ${ }^{a}$, Lydia Arfiantia ${ }^{a}$, Damayanti Tinduh ${ }^{a}$ \\ ${ }^{a}$ Physical Medicine and Rehabilitation Department, Faculty of Medicine Universitas Airlangga, Dr. Soetomo Academic General \\ Hospital, Surabaya, Indonesia \\ ${ }^{\mathrm{b}}$ Corresponding author: meiwulan21@gmail.com
}

\begin{abstract}
Background: As the prevalence is rising worldwide, overweight and obesity has become a major public health issue. Overweight and obese individuals had excess energy accumulation in the form of adipocyte tissue. High-intensity interval training (HIIT) is proposed as an exercise therapy option in weight reduction. Irisin, a myokine released after exercise, was thought to play a major role in weight reduction by browning adipocyte tissue. Therefore, this study aims to see how HIIT with changes in inclination affects irisin serum levels in overweight and obese men.

Methods: A randomized-controlled trial was conducted in rehabilitation outpatient clinic of Dr. Soetomo General Academic Hospital. Twenty-two subjects with overweight or obesity who meet research criteria were randomly allocated into intervention and control group. Intervention group received HIIT using treadmill (HR rest $+80-90 \%$ HR reserve) with inclination changes for 30 minutes (preceded by warming up and ending with cooling, 5 minutes each), 3 times a week, for 4 weeks. Control group received no intervention. Measurement of irisin serum levels in the intervention group was carried out before exercise, 30 minutes after first exercise, 30 minutes after last exercise, and one day after 4 weeks of exercise, while in the control group was carried out before and on one day after 4 weeks.

Results: No differences of body height, body weight, BMI, and VO2Max between groups $(\mathrm{p}<0.05)$. Subjects in control group are older than intervention group $(34.82 \pm 3.09$ vs $30.36 \pm 2.58, \mathrm{p}=0.002)$. Irisin serum levels was reduced 30 minutes after the first exercise $(\mathrm{p}=0.017)$ and after 4-weeks exercise program $(\mathrm{p}=0.006)$. Between groups comparison showed no difference in changes in irisin serum levels after 4 weeks between the two groups $(p=0.182)$, however glass delta mean effect size shows medium result (Glass's delta $=0.50$ ).

Conclusion: A significant reduction in irisin serum level may be correlated with reduction of adipose tissues and improvement of homeostasis after HIIT. High intensity interval training can be proposed as an exercise therapy option to support weight reduction in men with overweight and obesity. It is necessary to do further research on HIIT with a larger number of samples, longer time, group training and combined with other exercise such as resistance and flexibility exercises.
\end{abstract}

Keywords: rehabilitation; adipose tissue; exercise therapy; high-intensity interval training, Indonesia

\section{Introduction}

Obesity and overweight are major public health issues as their prevalence rises around the world, especially among adults in developed countries, where the incidence of obesity in women is far higher than in men. In 2014, 39 percent of adults worldwide were overweight, and 13\% were obese, making obesity one of the leading causes of death in many countries. Obesity rates in Indonesia increased rapidly from 14.8 percent in 2017 to 21.8 percent in 2018, indicating a rapid rise (Badan Penelitian dan Pengembangan Kementerian Kesehatan RI, 2018).

Overweight and obesity is characterized by excess adipocyte tissue which is induced by an imbalance energy metabolism due to excessive energy intake and inadequate energy expenditure (Gurevich-Panigrahi et al., 2009). Excessive absorption of energy is a result of high food intake, whereas inadequate energy are a 
result of poor body metabolism, low physical exercise and the food thermogenetic effect (Gurevich-Panigrahi et al., 2009). The risk factors of overweight and obesity are considered to be multifactorial and related to genetic and environmental factors (Gurevich-Panigrahi et al., 2009; Sartika, 2011).The progression of diabetes mellitus, insulin resistance, coronary disorders, alcohol-free fatty liver disease, endocrine diseases and even cancers are all linked to overweight and obesity (Gurevich-Panigrahi et al., 2009). Furthermore, overweight and obesity also causes a decrease in muscle mass, joint pain disorders, metabolic disorders, and psychological disorders (Barofsky et al., 1997; Fontaine et al., 1996). These disorders are associated with decreased fitness, emotional state, daily physical activity, and social interactions which lead to a lower quality of life among patient with overweight or obesity (Barofsky et al., 1997; Fontaine et al., 1996).

Although it is established that exercise has benefit in weight reduction, lack of time commonly prevents an individual from exercising regularly (American College of Sports Medicine, 2016). High-intensity interval training (HIIT) is suggested as an alternative to moderate intensity exercise to reduce overweight and obesity. High-intensity interval training consists of intensive exercise and rest periods which alternate with variations in intensity and length in each section of the exercise (Tolfrey \& Smallcombe, 2017).

One of the biomarkers that thought to bridge the role of exercise in weight reduction is irisin. Irisin is a polypeptide hormone derived from the cleavage of proteolytic fibronectin-type III domain containing 5 (FNDC5) protein (Archundia-Herrera et al., 2017). When irisin is released into the circulation, it stimulates white adipose tissue (WAT) browning which has the ability to directly transfer energy from nutrients to heat via uncoupling protein 1 (UCP1) (Norheim et al., 2014). Brown adipose tissue's appearance is particularly vulnerable to low atmospheric temperatures, which promote high glucose and fatty acid absorption and combustion (Norheim et al., 2014). Human brown adipose tissue function is also believed to associate negatively with body mass index, thus may be important to counteract obesity (Norheim et al., 2014). Therefore, based on the possible role of irisin in the benefit of exercise, the researcher aims to see how HIIT with changes in inclination affects irisin serum levels in overweight and obese men.

\section{Methods and Material}

This study is a randomized controlled trial involving 22 patients with overweight or obesity who were recruited from the rehabilitation outpatient clinic of Dr. Soetomo Academic General Hospital. Inclusion criteria used in this study were: 1.) male, 2.) age 18-55 years, 3.) normal cognitive function, 4.) Body Mass Index (BMI)> $22.9 \mathrm{~kg} / \mathrm{m} 2,5$.) systolic blood pressure $<140 \mathrm{mmHg}$ and diastole $<90 \mathrm{mmHg}$, and 6.) willing to participate in this research voluntarily by signing informed consent. Subjects were excluded if they had the following condition: 1.) routine aerobic exercise program 2 times a week, 2.) erythema, sores, ulcers or gangrene in the leg, 3.) peripheral neuropathy, 4.) area of motion of the joints of the two ankles for plantar flexion <45 degrees and dorsiflexion <30 degrees, 5.) restrictive or obstructive airway disease, 6.) neuromusculoskeletal disease of the lower limbs that interfere with ambulation function, 7.) impaired balance, and 8.) impaired vision.

Subjects that meet the criteria were then divided randomly into two groups, the intervention group, and the control group. The intervention group received HIIT using a treadmill (HR rest $+80-90 \%$ HR reserve) with periodical inclination changes for 30 minutes (preceded by warming up and ending with cooling, 5 minutes each), 3 times a week, for 4 weeks. The control group received no intervention and was educated to continue physical activity as usual.

The outcome of this study was irisin serum levels. Sampling of blood in the intervention group was carried out before the intervention, 30 minutes after the first intervention, 30 minutes after the last intervention, and one day after 4-weeks exercise program. Sampling of blood in the control group was carried out before and one day after 4 weeks. Blood samples were then analyzed using ELISA to measure irisin serum level. 
Statistical analysis was conducted using the Statistical Package for Social Sciences (SPSS). The characteristic baselines were compared using Independent T-Test and Mann-Whitney U Test. Glass's delta mean effect size was calculated to assess the size of the differences between groups. Mean effect size of $0.2-0.49$ was considered small, 0.5 - 0.79 was considered medium, and > 0.8 was considered large. This study was approved by the ethical committee of Dr. Soetomo Academic General Hospital.

\section{Results}

Demographic characteristic of research subjects is shown in table 1. The homogeneity test of subjects' baseline characteristics including body height, body weight, BMI, and VO2Max on both groups showed no significant differences $(\mathrm{p}<0.05)$, except for age which showed that subjects in control group are older than treatment group $(34.82 \pm 3.09$ vs $30.36 \pm 2.58, \mathrm{p}=0.002)$. The results of irisin serum level measurement were shown in table 2 . There were significant reductions of irisin serum levels 30 minutes after the first exercise (p $=0.017)$ and after 4 weeks of exercise $(p=0.006)$ in the intervention group. Comparative analysis between groups showed no difference in changes in irisin serum levels after 4 weeks between the intervention and control group $(-39.84 \pm 190.30$ vs $-136.18 \pm 128.29, \mathrm{p}=0.179)$. Glass delta mean effect size analysis shows medium result (Glass's delta $=0.50)$.

Table 1. Demographic characteristic of research subjects

\begin{tabular}{lccc}
\hline \multicolumn{1}{c}{ Characteristics } & Intervention Group $(\mathrm{n}=11)$ & Control Group $(\mathrm{n}=11)$ & $\mathrm{p}$ \\
\hline Age $($ years $)$ & $30.36 \pm 2.58$ & $34.82 \pm 3.09$ & $0.002 *$ \\
Body height $(\mathrm{cm})$ & $167.91 \pm 5.92$ & $167.36 \pm 6.27$ & 0.836 \\
Body weight $(\mathrm{kg})$ & $81.00 \pm 12.51$ & $76.36 \pm 10.44$ & 0.357 \\
BMI $\left(\mathrm{kg} / \mathrm{m}^{2}\right)$ & $28.63 \pm 3.32$ & $27.18 \pm 2.61$ & 0.268 \\
VO2Max & $28.46 \pm 2.95$ & $27.15 \pm 4.43$ & 0.479 \\
Irisin serum levels $(\mathrm{ng} / \mathrm{ml})$ & $281.41 \pm 145.46$ & $277.02 \pm 265.68$ & 0.491 \\
\hline
\end{tabular}

$* \mathrm{p}<0.05$

Table 2. Irisin serum levels change in intervention and control group

\begin{tabular}{lccc}
\hline & Intervention Group & $\mathrm{P}$ & Control Group \\
\hline Baseline & $281.41 \pm 145.46$ & & $277.02 \pm 265.68$ \\
30 minutes after first exercise & $171.93 \pm 82.59$ & $0.017^{*}$ & \\
30 minutes after last exercise & $172.19 \pm 61.27$ & 0.254 & \\
After 4 weeks & $145.23 \pm 100.28$ & $0.006^{*}$ & $237.18 \pm 161.08$ \\
\hline$* \mathrm{p}<0.05$ & & & 0.182 \\
\hline
\end{tabular}

$* \mathrm{p}<0.05$

Table 3. Comparison of irisin serum levels change after 4 weeks

\begin{tabular}{lccc}
\hline Characteristics & Intervention Group & Control Group & $\mathrm{p}$ \\
\hline$\Delta$ Irisin serum level $(\mathrm{ng} / \mathrm{ml})$ & $-136.18 \pm 128.29$ & $-39.84 \pm 190.30$ & 0.179 \\
\hline
\end{tabular}

\section{Discussion}

The result of present study shows that HIIT decrease irisin serum levels acutely before intervention (30 minutes after first exercise) and after 4-weeks exercise program. Mean effect size analysis indicated that the decrease of irisin serum levels after 4 weeks in intervention group was also different from control group. The acute effect of HIIT on irisin serum levels. Interestingly, the acute reduction effect was not found after the 
subject finish 4-weeks exercise program. In fact, there was a slight increase of irisin serum levels 30 minutes after the last exercise. These findings of acute effect were contrary to the findings of who indicated

The effect of 4-weeks HIIT program in this study is in line with previous studies reporting decrease of irisin serum levels after 12-weeks HIIT program (Safarimosavi et al., 2018) and 12-weeks of combined endurance and strength training in overweight and prediabetic men (Norheim et al., 2014). A meta-analysis study on chronic exercise training and irisin in adults by Qiu et al. (2015) concluded that chronic exercise training (more than 8 weeks) significantly reduces irisin serum levels. However, in contrast with present study, Pekalla showed that irisin did not change after acute aerobic, long-term endurance training or endurance training combined with resistance exercise (2013). In contrast with the two studies, Archundia-Herrera found that a session of HIIT may significantly increase the levels of expression of irisin in skeletal muscle, while aerobic exercise has no effect on irisin levels (2017).

Several possibilities may be considered in the reduction of irisin serum levels after exercise. Firstly, change of irisin serum levels may be determined by change of irisin production in various organ. Irisin is both a myokine released by muscle tissue and an adipokine released by adipose tissue (Roca-Rivada et al., 2013), therefore, irisin serum levels may be reduced along with the reduction of body fat and mass after exercise (Safarimosavi et al., 2018). Secondly, strong association between circulating irisin and homeostatic indicators were found in cross-sectional studies, including fasting blood glucose and insulin-resistance (Safarimosavi et al., 2018). Irisin is assumed to have increased release by adipose / muscle tissue as compensation to counter the physiological effects of poor insulin function stimulating glucose uptake by increasing GLUT4 via AMPK activation (Safarimosavi et al., 2018). Therefore, along with the improvement of insulin resistance associated with chronic physical exercise, the circulating irisin will also decrease (Safarimosavi et al., 2018).

It is important to note that use of irisin serum levels as biomarker of physical exercise and weight reduction has several limitations. According to Raschke et al., most of the translated human FNDC5 protein as the source of irisin lose nearly 50\% of the irisin sequence (Raschke et al., 2013). The human FNDC5 gene may be a transcribed pseudogen that has substantially lost the ability to translate the intact FNDC5 protein so that it cannot be processed into irisin. The low translation efficiency may be due to mutations in the initial codon of the human FNDC5 gene (Raschke et al., 2013). As a result, irisin should be difficult to detect in humans or only detectable in low concentrations (Raschke et al., 2013). Furthermore, commercial ELISA test kits used to assess irisin levels has a very wide sensitivity range (Albrecht et al., 2015). Polyclonal antibodies used to assess irisin levels in ELISA test kits often cross-react with non-specific proteins, therefore when it is used to detect irisin in a sample of a complex protein such as plasma or serum, a signal is received not only from irisin but also from other proteins that have cross-reactions, some of which may have high levels and can dominate the signal (Albrecht et al., 2015). Other factors that may affect measurement of irisin serum levels include storage time of blood samples and timing of blood samples (Qiu et al., 2015).

\section{Conclusion}

A significant decrease of irisin levels after HIIT may indicates reduction of adipose tissue and better homeostasis, therefore HIIT can be recommended for men with overweight and obesity to support weight reduction. More study on HIIT needs to be conducted with a wider range of samples, longer duration, group training and in conjunction with other exercise such as resistance and balance.

\section{References}

Albrecht, E., Norheim, F., Thiede, B., Holen, T., Ohashi, T., Schering, L., Lee, S., Brenmoehl, J., Thomas, S., Drevon, C. A., Erickson, H. P., \& Maak, S. (2015). Irisin - a myth rather than an exercise-inducible myokine. 1-10. https://doi.org/10.1038/srep08889 American College of Sports Medicine. (2016). ACSM's Guidelines for Exercise Testing and Prescription (9th ed.). Lippincott Williams 
\& Wilkins.

Archundia-Herrera, C., MacIas-Cervantes, M., Ruiz-Muñoz, B., Vargas-Ortiz, K., Kornhauser, C., \& Perez-Vazquez, V. (2017). Muscle irisin response to aerobic vs HIIT in overweight female adolescents. Diabetology and Metabolic Syndrome, 9(1), 5-11. https://doi.org/10.1186/s13098-017-0302-5

Badan Penelitian dan Pengembangan Kementerian Kesehatan RI. (2018). Laporan Nasional Riset Kesehatan Dasar 2018. Badan Penelitian dan Pengembangan Kesehatan Kementerian Kesehatan RI.

Barofsky, I., Fontaine, K. R., \& Cheskin, L. J. (1997). Pain in the obese: impact on health-related quality-of-life. Annals of Behavioral Medicine, 19(4), 408-410.

Fontaine, K. R., Cheskin, L. J., \& Barofsky, I. (1996). Health-related quality of life in obese persons seeking treatment. Journal of Family Practice, 43(3), 265-270.

Gurevich-Panigrahi, T., Panigrahi, S., Wiechec, E., \& Los, M. (2009). Obesity: pathophysiology and clinical management. Current Medicinal Chemistry, 16(4), 506-521. https://doi.org/10.2174/092986709787315568

Norheim, F., Langleite, T. M., Hjorth, M., Holen, T., Kielland, A., Stadheim, H. K., Gulseth, H. L., Birkeland, K. I., Jensen, J., \& Drevon, C. A. (2014). The effects of acute and chronic exercise on PGC-1 $\alpha$, irisin and browning of subcutaneous adipose tissue in humans. FEBS Journal, 281(3), 739-749. https://doi.org/10.1111/febs.12619

Pekkala, S., Wiklund, P. K., Hulmi, J. J., Ahtiainen, J. P., Horttanainen, M., Pöllänen, E., Mäkelä, K. A., Kainulainen, H., Häkkinen, K., Nyman, K., Alén, M., Herzig, K. H., \& Cheng, S. (2013). Are skeletal muscle FNDC5 gene expression and irisin release regulated by exercise and related to health? Journal of Physiology, 591(21), 5393-5400. https://doi.org/10.1113/jphysiol.2013.263707

Qiu, S., Cai, X., Sun, Z., Schumann, U., Zügel, M., \& Steinacker, J. M. (2015). Chronic exercise training and circulating irisin in adults: a meta-analysis. Sports Medicine, 45(11), 1577-1588.

Raschke, S., Elsen, M., Gassenhuber, H., Sommerfeld, M., Schwahn, U., Brockmann, B., Jung, R., Wisløff, U., Tjønna, A. E., \& Raastad, T. (2013). Evidence against a beneficial effect of irisin in humans. PloS One, 8(9), e73680.

Roca-Rivada, A., Castelao, C., Senin, L. L., Landrove, M. O., Baltar, J., Crujeiras, A. B., Seoane, L. M., Casanueva, F. F., \& Pardo, M. (2013). FNDC5/irisin is not only a myokine but also an adipokine. PloS One, 8(4), e60563.

Safarimosavi, S., Mohebbi, H., \& Rohani, H. (2018). High-Intensity Interval vs. Continuous Endurance Trainig: Preventive Effects on Hormonal Changes and Physiological Adaptations in Prediabetes Patients. 00(00), 1-8.

Sartika, R. A. D. (2011). Faktor risiko obesitas pada anak 5-15 tahun di Indonesia. Makara Kesehatan, 15(1), 37-43.

Tolfrey, K., \& Smallcombe, J. (2017). High-intensity interval training. In N Amstrong \& W. Van Mechelen (Eds.), Oxford Textbook pf Children's Sport and Exercise Medicine (pp. 477-491). Loughborough University. 